\title{
Usuários da informação com deficiência e o papel das bibliotecas universitárias
}

\author{
Users of information with disabilities and the role of university libraries
}

\author{
Michelle Karina Assunção Costa \\ Doutoranda em Gestão e Organização do Conhecimento \\ Universidade Federal de Minas Gerais \\ michelleassuncao@gmail.com
}

Dalgiza Andrade Oliveira

Doutora em Ciência da Informação

Universidade Federal de Minas Gerais

dalgizamg@gmail.com

\begin{abstract}
Resumo
A presença de discentes que se declaram com deficiência no ensino superior sinaliza para que as bibliotecas universitárias avaliem os seus produtos e serviços na perspectiva da acessibilidade e inclusão. Nessa direção, o presente artigo de revisão tem o objetivo de refletir acerca da acessibilidade, dos usuários com deficiência e o papel das bibliotecas. Por meio de uma pesquisa bibliográfica, documental e de abordagem qualitativa realizou-se um levantamento bibliográfico de investigações no contexto da acessibilidade e inclusão realizadas em Programas de Pós-graduação em Ciência da Informação no Brasil e a consulta a documentos normativos como leis, decreto, artigos entre outros que subsidiam a discussão proposta. Na análise dos resultados das investigações associada com as orientações para a acessibilidade e os relatos dos usuários com deficiência visual observa-se que as unidades de informação, ainda, estão inacessíveis. Pois, falta pessoal capacitado, os usuários têm dificuldades de acesso à informação, existem barreiras na dimensão arquitetônica, comunicacional, atitudinal etc. Esse cenário sinaliza que ainda há bastante trabalho e ações a desenvolver para a concepção de bibliotecas acessíveis.
\end{abstract}

\section{Palavras-chave}

Usuários. Acessibilidade. Comportamento do usuário. Gestão de bibliotecas. Bibliotecas universitárias.

\begin{abstract}
The presence of students who declare themselves disabled in higher education signals that university libraries evaluate products and services from the perspecive of accessibility and inclusion. In this direction, this review article aims to reflect on accessibility, users with disabilities and the role of libraries. Through a bibliographic, documentar and qualitative research, a bibliographic survey of investigations in the contexto of accessibility and inclusion post-graduate programs in Information Science in Brazil and consultation with normative documents such as laws, decree, articles among others tha support the proposed discussion. In the analysis of the results of investigations associatec wiht the guidelines for accessibility and the reports of users visually impaired, it is observed that the units of information are still inacessible. Because, lack of qualified personnel, user have difficulties in accessing information, there are barriers in the architectural, communicational, aitudinal dimension etc. This scenario signals that there is still a lot of word and actions to bem developed for the design of accessible libraries.
\end{abstract}




\section{Keywords}

Users. Accessibility. User behavior. Library management. University libraries.

\section{INTRODUÇÃO}

Os usuários da informação, cotidianamente, têm necessidades de informação e as utilizam para resolverem diferentes problemas estando elas associadas com as tarefas que realizam no âmbito pessoal e/ou profissional. De acordo com os autores Cunha, Amaral e Dantas (2015), são vários os tipos de usuários, podendo mencionar: usuários potenciais, usuários reais, não usuários, usuários infantis, usuários de bibliotecas, usuários de arquivos, usuários com deficiência, dentre outros. Infere-se, portanto, que diante dessa diversidade de usuários as bibliotecas, independente da sua tipologia, têm a indispensabilidade de atender às demandas informacionais de todos equitativamente.

Em face do exposto, a presente discussão observa a categoria de usuários com deficiência que podem ter deficiências visuais, auditivas, físicas, distúrbios de aprendizagem, síndromes, deficiências múltiplas entre outras. Ou seja, podem ser pessoas com deficiências visíveis ou não aparente. Assim sendo, tem-se o objetivo de refletir acerca da acessibilidade, dos usuários com deficiência e o papel das bibliotecas universitárias. Pois, tem-se a compreensão de que mesmo com esse diálogo sendo realizado na Biblioteconomia e na Ciência da Informação $(\mathrm{Cl})$ ao longo dos anos visualiza-se, ainda, a inacessibilidade nestes espaços se o usuário da informação for uma pessoa com deficiência (PCD). Visto que os espaços sociais, incluindo as BU, não estão preparadas como dispõem os subsídios legais, por exemplo, o que pode acarretar a exclusão impedimentos, barreiras, fronteiras sociais que dividem grupos-, dessas pessoas no uso das bibliotecas e no acesso à informação. A presente afirmação fundamenta-se nos resultados de pesquisas na $\mathrm{Cl}$ acerca dessa temática que faz parte da tese do doutorado, em andamento, no Programa de Pós-Graduação em Gestão \& Organização do Conhecimento (PPGCOC) na Universidade Federal de Minas Gerais (UFMG). Assim, pode-se justificar essa reflexão do ponto de vista científico e social. E no tocante ao cunho pessoal a investigação dá continuidade ao estudo iniciado nesta temática no mestrado em $\mathrm{Cl}$ e com os resultados observados, bem como a fatos que ocorreram na prática profissional no contato com usuários com deficiências na BU.

Perante ao exposto, compreende-se que, os gestores das BU ao conhecerem os usuários da informação e as suas singularidades podem por meio de estratégias e de uma gestão inclusiva eliminar barreiras na busca, acesso e uso de informações, bem como de disseminar informações acessíveis (CERQUEIRA, 2019). Diante disso, entendese que com esse olhar e responsabilidade social seja possível diminuir a exclusão no âmbito das unidades de informação (UI) pois, as demandas informacionais das PCD seriam atendidas.

Nessa direção, o presente artigo de revisão discorre sobre a indispensabilidade das BU por meio de seus gestores conhecerem a diversidade de usuários que se declaram com deficiência nas Instituições de Ensino Superior (IES) e que estão ao seu redor. E dessa forma terem condições de atenderem às demandas desse público da mesma maneira que fazem com os usuários que não têm deficiência propiciando a esses cidadãos terem os mesmos direitos das pessoas sem deficiência no universo das BU. Portanto, problematiza-se se esse usuário da informação com deficiência, que ainda pode 
ser desconhecido por muitos bibliotecários, tem o mesmo acesso à informação como aquele que não tem deficiência.

Acerca da importância de conhecer a sua comunidade, ou seja, os seus sujeitos informacionais, os autores Rendón-Rojas e García-Cervantes explicitam que uma das tarefas dos profissionais da informação é a de organizar a informação documental, mas é indispensável conhecer os sujeitos que demandam por informações e conhecimento. Outra tarefa é a pesquisa comunitária em que será estudada as realidades informacionais dos espaços em que os sujeitos informacionais hoje se encontram e requerem e/ou constroem novas formas de organização e estrutura da informação inerente ao seu contexto social, educacional, de trabalho entre outros (tradução nossa). ${ }^{1}$

Ressalta-se que as PCD vêm, ao longo de anos, buscando o seu espaço na sociedade brasileira e lutando para que se cumpram os seus direitos (LANNA JUNIOR, 2010; BRASIL, 2015). E a partir do momento que elas vão ocupando os mais variados espaços sociais tem-se o entendimento que é preciso conhecê-los de forma que suas demandas possam ser atendidas. Assim, por essas e outras razões, entende-se a relevância dessa discussão nas referidas áreas de conhecimento que investigam a organização, disseminação e gestão da informação e do conhecimento, no espaço físico e virtual, a recuperação da informação, desenvolvem softwares, realizam estudos de usuários etc. Considera-se que esses aspectos estão diretamente ligados a um usuário da informação e que esse usuário pode ser uma PCD. Sendo assim, tem-se a percepção de que nestes aspectos poder-se-ia refletir acerca da acessibilidade e incluir esse público em futuras investigações. Pois, como qualquer outro indivíduo as PCD fazem uso da informação para tomada de decisão cotidianamente e tem o seu comportamento informacional em relação as suas necessidades, à busca, o acesso e ao uso da informação.

\section{METODOLOGIA}

O presente artigo de revisão apresenta parte de um levantamento da literatura científica da pesquisa de doutorado, em andamento, acerca da gestão de BU na perspectiva da diversidade. Trata-se, portanto, de uma pesquisa documental, bibliográfica e de abordagem qualitativa.

Para a construção do referencial teórico no que concerne a pesquisa documental realizou-se buscas na internet da legislação brasileira acerca dos direitos das PCD, dados do Censo da Educação Superior para conhecimento da presença de discentes com deficiência no ensino superior e da literatura nacional e internacional que discorrem acerca da temática em questão e que possibilita realizar uma revisão narrativa. Esse tipo de revisão tem uma temática mais livre, sem o requisito de um protocolo rígido e a busca pelas fontes informacionais não é pré-determinada (CORDEIRO; OLIVEIRA; RENTERÍA; GUIMARÃES, 2007). Os artigos de revisão narrativa são apropriados

\footnotetext{
${ }^{1}$ De las tareas de los profesionales de la información ha sido la de organizar la información documental, pero para ello es primordial conocer a la comunidad de sujetos que demandan informaciónconocimiento. Es decir, que otra tarea es la investigación de la comunidade, estudiar las realidades informacionales de los espacios concretos en donde los sujetos informacionales de hoy en día requieren y/o están construyendo nuevas formas de organización y estructuras de la información ad hoc a su contexto social, político, educativo, cultural, contracultural, laboral, religioso, ideológico, etcétera. (RENDÓN-ROJAS; GARCÍA-CERVANTES, 2012, p. 38)
} 
para discutir e descrever o estado da arte de um determinado tema, sob os pontos de vistas teórico ou contextual. "Constitui-se, portanto, na interpretação e análise crítica do autor da literatura publicada em revistas, livros etc." (ROTHER, 2007, p. v).

Ao que se refere a pesquisa bibliográfica - teses e dissertações-, realizou-se a busca no Catálogo de Teses e Dissertações da Coordenação de Aperfeiçoamento de Pessoal de Nível Superior (CAPES), no site da Biblioteca Digital de Teses e Dissertações da UFMG, na Biblioteca Digital Brasileira de Teses e Dissertações (BDTD) e na Biblioteca Digital de Teses e Dissertações da Pontifícia Universidade Católica (PUC) Campinas. Utilizou-se palavras-chave como: biblioteca universitária e acessibilidade, acessibilidade e pessoa com deficiência, audiodescrição, acessibilidade informacional, usuário com deficiência, inclusão e biblioteca, pessoas com deficiência e biblioteca, tecnologia assistiva (TA), acessibilidade e usuários com deficiência. A busca recuperou investigações que foram realizadas entre os anos de 2006 e 2019 e que vão ao encontro da proposta da pesquisa e que serão apresentadas na tese. Para este artigo realizou-se um recorte desse levantamento e escolheu, intencionalmente, apresentar somente estudos do ano 2019 por estes serem mais recentes e compartilhar parte dos seus resultados com o intuito de mostrar qual é a realidade do usuário com deficiência ao utilizar as BU, bem como contribuir para uma reflexão dessa temática no universo das BU.

Dessa forma, a amostra apresentada corresponde a uma tese e quatro dissertações que realizadas nos Programas de Pós-Graduação em $\mathrm{Cl}$ da Universidade de Brasília (UnB), Universidade Federal da Bahia (UFBA), Universidade Federal do Pará (UFPA), Universidade Federal do Sergipe (UFS) e na Universidade do Estado de Santa Catarina (UDESC). Portanto, o critério de escolha para a presente amostra foi exclusivamente o ano de publicação. Os resultados apresentados seguem a redação dos seus autores e de trechos dos seus interlocutores realizando-se inferências para a discussão dos resultados.

\section{USUÁRIOS COM DEFICIÊNCIA NO ENSINO SUPERIOR E AS BIBLIOTECAS UNIVERSI- TÁRIAS}

Refletir acerca da acessibilidade nas BU deve-se a alguns aspectos que são considerados pertinentes para a concepção de bibliotecas brasileiras acessíveis e, consequentemente, podem contribuir para a diminuição da exclusão e desigualdades sociais nesses espaços. Pois, conforme mencionado pelos autores Lemos e Chanini (2019, p. 32524), "os serviços de uma biblioteca se baseiam na igualdade de acesso para todos".

Inicialmente, tem-se o entendimento que é indispensável ter a compreensão que quando se fala nesse assunto deve-se ao fato de se tratar do direito das PCD. Pois, de acordo com a Lei Brasileira da Inclusão (BRASIL, 2015, online), Art. 4, "toda pessoa com deficiência tem direito à igualdade de oportunidades com as demais pessoas e não sofrerá nenhuma espécie de discriminação". Ao observar a referida Lei no contexto das atividades das BU pode-se destacar: a PCD tem direito a receber atendimento prioritário - atendimento em todas as instituições e serviços de atendimento ao público-, disponibilização de recursos humanos e tecnológicos para garantir atendimento em igualdade de condições com as demais pessoas e o acesso à informação e disponibilização de recursos de comunicação acessíveis. Evidencia-se, também, o direito à 
educação, sendo este um espaço em que várias bibliotecas se fazem presentes. De acordo com o que dispõe o Art. 27 da referida Lei,

\begin{abstract}
a educação constitui direito da pessoa com deficiência, assegurados sistema educacional inclusivo em todos os níveis e aprendizado ao longo de toda a vida, de forma a alcançar o máximo desenvolvimento possível de seus talentos e habilidades físicas, sensoriais, intelectuais e sociais, segundo suas características, interesses e necessidades de aprendizagem (BRASIL, 2015, online).
\end{abstract}

Outro ponto da Lei que dialoga com o presente artigo é a acessibilidade. O Art. 53 dispõe que "a acessibilidade é direito que garante à pessoa com deficiência ou com mobilidade reduzida viver de forma independente e exercer seus direitos de cidadania e de participação social." (BRASIL, 2015, online). No contexto da acessibilidade a informação, o Capítulo II da Lei discorre acerca Do Acesso à Informação e à Comunicação. Neste tópico evidencia-se: acessibilidade nos sítios da internet - os sítios devem conter símbolo de acessibilidade em destaque; formatos acessíveis - arquivos digitais que podem ser reconhecidos e acessados por programas leitores de telas e outras tecnologias assistivas (TA) que permita a leitura com voz sintetizada; a ampliação de caracteres, contrastes e impressão em Braille e, mais especificamente, no universo das bibliotecas a Lei dispõe que

nos editais de compras de livros, "inclusive para o abastecimento ou a atualização de acervos de bibliotecas em todos os níveis e modalidades de educação e de bibliotecas públicas, o poder público deverá adotar cláusulas de impedimento à participação de editoras que não ofertem sua produção também em formatos acessíveis (BRASIL, 2015, online).

Sobre o uso dos espaços das BU pelas PCD, encontra-se no Art. 117 da Lei Brasileira de Inclusão que é assegurado o direito à $P C D$ visual acompanhada do cão-guia de ingressar e permanecer com o animal em todos os espaços abertos ao público e de uso público e privado de uso coletivo, nos meios de transportes de acordo com o que dispõe a Lei (BRASIL, 2015, online).

Ao mencionar o direito das PCD, vale destacar que "o conjunto das leis brasileiras destinadas aos direitos das pessoas com deficiência é reconhecido como um dos mais abrangentes do mundo" (MAIOR, 2017, p. 32). Mas, conforme mencionado na tese de Malheiros (2019, p. 64), "na prática essas leis, na sua maioria, não são cumpridas ou são cumpridas em parte, por falta de uma fiscalização eficaz que garanta o seu cumprimento". Dentre os vários motivos para o seu não cumprimento pode-se citar: "desconhecimento, preconceito, cultura, falta de vontade e de políticas públicas" (YOSHIDA, 2008, p. 20).

A Agenda 2030, da Organização das Nações Unidas (ONU, 2016), também faz parte da literatura acerca dessa temática tendo a compreensão de que ela pode contribuir para a acessibilidade nas bibliotecas. Essa Agenda é um plano de ação para as pessoas, para o planeta e para a prosperidade a ser desenvolvido por meio dos $17 \mathrm{Ob}$ jetivos de Desenvolvimento Sustentável (ODS). Visualiza-se que por meio dos ODS é possível construir uma sociedade para todos em que se busca a igualdade de oportunidades para os cidadãos e, como resultado, propicia a redução das desigualdades. $\mathrm{E}$ 
sabe-se que as PCD ao longo dos anos vêm cotidianamente passando por situações de desigualdades inclusive no universo das BU.

Outro ponto relevante são os dados do Censo da Educação Superior do Instituto Nacional de Estudos e Pesquisas Educacionais Anísio Teixeira (2017), de discentes na graduação que se declararam com deficiência. De acordo com esses dados os estudantes declaram ter autismo, baixa visão, cegueira, deficiência auditiva, deficiência física, deficiência intelectual, deficiência múltipla, Síndrome de Asperger, Síndrome de Rett, superdotação, surdez, surdocegueira e transtorno desintegrativo conforme pode ser visualizado na Fig. 1.

Figura 1 - Tipologias de deficiência dos discentes no ensino superior

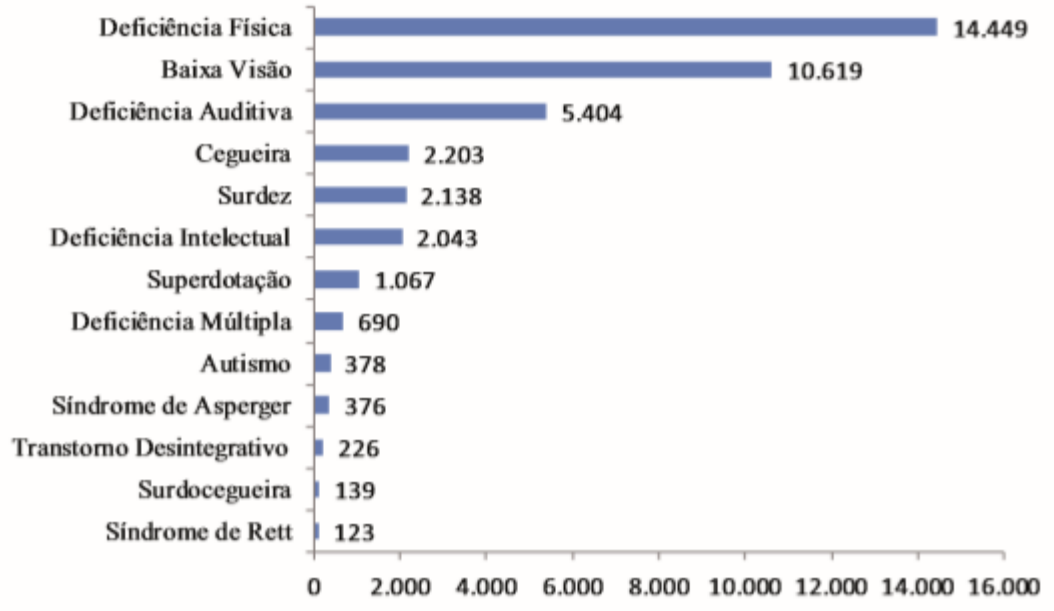

Fonte: Instituto Nacional de Estudos e Pesquisas Educacionais Anísio Teixeira (2017)

Diante do exposto, compreende-se que desafios serão impostos à prática profissional do bibliotecário e ao papel das bibliotecas em dar condições de acesso a essa multiplicidade de sujeitos informacionais ${ }^{2}$ (RENDÓN-ROJAS; GARCÍA-CERVANTES, 2012) no ensino superior. À vista disso, existe uma variedade de objetos de estudo que podem ser estudados em futuras investigações na $\mathrm{Cl}$.

O trabalho Library Service to People with Disabilities ${ }^{3}$ apresentado na ONU no ano de 2017 por Bolt e Wyber discorre acerca de uma pesquisa realizada em todo o mundo sobre práticas e políticas de bibliotecas para as PCD. No referido trabalho menciona-se que barreiras podem ser um dos motivos que dificultam a implementação de serviços acessíveis nas bibliotecas para esse público, a saber: falta de recursos e de pessoal capacitado e de avaliar os resultados.

Outro documento no contexto internacional é o Accessibility Information Toolkit for Libraries (2014). Ele é um kit de informações acerca da acessibilidade para bibliotecas produzido pelas Bibliotecas da Universidade de Toronto no Canadá. Esse material fornece exemplos de práticas de acessibilidade no contexto de $\mathrm{BU}$, mas que pode ser adaptado em conformidade com a instituição. O documento aborda os serviços que compreende a acessibilidade comunicacional refletindo em quais tipos de co-

\footnotetext{
${ }^{2}$ El sujeto interpela para demandar, construir y articular nuevas estructuras socioinformativas para actuar en esa coyuntura social, como es el caso de las bibliotecas comunitárias por ejemplo, para responder a la necesidades informativas concretas del espacio societal (RENDÓN-ROJAS; GARCÍA-CERVANTES, 2012, p. 36-37).

${ }^{3}$ Serviço de biblioteca para pessoas com deficiência. (BOLT; WYBER, 2017, tradução nossa).
} 
municação precisam ser acessíveis nas bibliotecas, discorre acerca das barreiras que os discentes com deficiência enfrentam dentre outros aspectos.

Ao observar os dados de PCD nas IES considera-se que eles possam ser um indicador relevante para a gestão das BU na perspectiva da diversidade. Sabendo que cada indivíduo é único e singular e com suas preferências e necessidades para busca, acesso e uso da informação, infere-se que seja preciso avaliar os serviços que atualmente são disponibilizados e repensar novas formas de atender as demandas de um público que pode ser desconhecido para alguns gestores. Vale lembrar que a BU "é mantida por uma instituição de ensino superior e que atende as necessidades de informação dos corpos docente, discente e administrativo, tanto para apoiar as atividades de ensino, quanto de pesquisa e extensão" (CUNHA; CAVALCANTI, 2008, p. 53). E nessa comunidade interna da IES pode ter PCD de nascença ou adquirida, esta segunda pode ocorrer em decorrência de sequelas de acidentes, idade ou doenças, por exemplo. Destaca-se que no Brasil há legislação para cotas de PCD em concurso público, para o acesso ao ensino superior e para a contratação em empresas privadas (BRASIL, 1991; BRASIL, 2016; BRASIL, 2018).

Diante desse contexto compreende-se que os bibliotecários poderiam se apropriar dessa questão para disponibilizarem bibliotecas acessíveis a esse público. Em vista disso, entende-se que o bibliotecário tem um importante papel a desempenhar para realizar uma gestão inclusiva nos espaços das bibliotecas tendo a percepção de que é a partir dele que a inclusão nas UI pode começar a ser praticada. Mas depreende-se que esse trabalho deverá ser em conjunto com a instituição em que a BU está inserida. Para isso, há a necessidade de se criar uma cultura inclusiva nas instituições seja por meio de uma política institucional, ou ações inclusivas em que toda a comunidade acadêmica, seja ela pública ou privada, esteja comprometida com essa questão.

Nesta direção, as práticas inclusivas contemplarão as dimensões da acessibilidade podendo mencionar a acessibilidade informacional que "é a dimensão que determina a eliminação de barreiras no acesso à informação para auxiliar no alcance às fontes e materiais de informação para todas as pessoas de forma segura e autônoma". (SANTOS; ARAÚJO, 2015, p. 2010), Ela é uma ferramenta importante para que ocorra a inclusão social (FERNANDES, 2018).

Segundo os autores Medeiros e Presser (2020), para a promoção da inclusão social os profissionais da informação precisam assumir o desafio de elaborar estratégias para romper com os contextos de pobreza informacional propiciando o desenvolvimento da autonomia informacional dos usuários de forma que contribua para a garantia do direito à informação, à leitura, à cultura e à memória.

\subsection{Acessibilidade nas Bibliotecas Universitárias}

As BU podem contribuir para uma sociedade para todos ao incluir essa temática na sua gestão e, como resultado, disponibilizaria produtos e serviços acessíveis, pessoal capacitado para o atendimento as PCD, diminuiria ou até eliminaria barreiras. Consequentemente, implementariam ações que contemplam as dimensões da acessibilidade arquitetônica, comunicacional, atitudinal, metodológica, informacional entre outras (SASSAKI, 2006; NICOLETTI, 2010).

Tem-se a compreensão de que a partir do momento que as UI começam a criar e disponibilizar serviços, produtos, acervo acessível e ouvir os seus usuários elas assu- 
mem o seu compromisso social com esta questão. Pois, estariam atentas ao seu ambiente externo para realizar uma gestão de bibliotecas para a multiplicidade de usuários. Pondera-se que essa postura contribua para acolher, respeitar as diferenças, incluir esse público nas BU e dar condições das PCD realizarem o seu percurso acadêmico. Destaca-se aqui o valor da comunicação organizacional e o trabalho em parceria com outros setores das IES que têm um contato mais estreito com esses discentes, como, por exemplo, os núcleos de apoio e inclusão ao discente que se declara com deficiência nas IES. Visto que essa responsabilidade é de todos os cidadãos brasileiros e o processo de inclusão é um trabalho realizado diariamente, é dinâmico e não tem fim (BOOTH; AINSCOW, 2011).

Segundo Campos (2014), alguns aspectos podem ser considerados para a evasão no ensino superior e infere-se que talvez alguns deles possam estar presentes no universo das BU, ocasionando o distanciamento desse público nesse espaço social. Os aspectos mencionados pelo autor são: pouca efetividade das políticas de acesso e permanência no ensino; despreparo dos professores e demais profissionais para realizarem um trabalho efetivo com essa demanda; fatores idiossincráticos, além dos aspectos históricos, culturais, sociais, econômicos; elitização do ensino superior e pouco acesso para as classes menos favorecidas; precarização do ensino fundamental e médio também contribuem para a evasão, uma vez que constitui-se como base imprescindível para o conhecimento que será aprimorado na educação superior; preconceito e falta de conhecimento dos docentes para trabalhar com uma PCD etc. Logo, sendo as BU parte da infraestrutura das IES e avaliada pelo Ministério da Educação em aspectos que contemplam também a acessibilidade, essa temática tornase, portanto, indissociável ao contexto de atuação do bibliotecário e das BU.

Nessa direção, apresentam-se alguns dos resultados das pesquisas de Malheiros (2019), Cerqueira (2019), Pinheiro (2019), Santos (2019) e Santos (2019a) realizadas em Programas de Pós-Graduação em $\mathrm{Cl}$ que permite saber como as temáticas da acessibilidade e inclusão estão sendo investigadas na $\mathrm{Cl}$ no Brasil, como estão as $\mathrm{BU}$ nessa questão e conhecer a percepção dos usuários da informação com deficiência acerca das bibliotecas que eles utilizam. Informa-se que um panorama maior sobre essas investigações fará parte da tese do doutorado no PPGGOC. Salienta-se que as passagens apresentadas são escritas pelos autores das pesquisas e ao longo do texto ocorrem algumas inferências para o diálogo com o objetivo proposto por esse artigo.

A tese de Malheiros (2019), intitulada Produtos e serviços de informação para pessoas com deficiência visual teve como objetivo geral identificar os produtos e serviços de informação (PSI) que são ofertados pelas UI para as pessoas com deficiência visual (PDV). Na leitura dos seus resultados destaca-se que: o leitor de telas mais ofertado pelas UI são o NVDA, Dosvox, JAWS e Virtual Vision; os cinco produtos de informação mais disponibilizados são os ampliadores de tela $(60,74 \%)$; audiolivros (58,96\%); recursos em Braille (58,46\%); computadores com leitores de tela (52,27\%) e livros com fonte ampliada (50,76\%). As razões da não oferta de determinados PSI, segundo os gestores entrevistados, deve-se à questão financeira, sendo quase unânime como justificativa. E menciona-se a falta de apoio administrativo como sendo a principal causa da não oferta desses PSI. Percebe-se como é importante uma política de inclusão nas instituições que possa colaborar para a criação de ações inclusivas e serviços acessíveis. Um gestor mencionou que parcerias podem ser realizadas como solução ou um serviço de ledores. A falta de consciência é apontada como causa da não 
oferta dos PSI. Pelos dados coletados, observou-se que a maioria dos PSI ofertados para usuários com deficiência visual foram criados nos últimos 30 anos. Isto posto, demonstra-se a necessidade de capacitação das equipes da BU para aquisição de novos conhecimentos, habilidades e atitudes para mudar esse cenário. Pois, o que há anos supria a necessidade informacional de uma PDV hoje os PSI tendem a estar defasados.

A inclusão da pessoa com deficiência visual sob a perspectiva da ciência da informação: um estudo nas bibliotecas da Universidade Federal do Recôncavo da Bahia (UFRB) foi o estudo realizado por Cerqueira (2019). O objetivo geral da presente pesquisa pautou-se em conhecer as condições de inclusão para PCD visual nas bibliotecas da UFRB e investigar a efetividade, ou seja, o efeito concreto da produção da área da $\mathrm{Cl}$ para a inclusão desses indivíduos. Os resultados da dissertação demostram que no quesito acesso, praticamente, todas as bibliotecas têm difícil localização em bairros afastados do centro. Em duas bibliotecas a situação é amenizada porque o ônibus da universidade realiza o transporte dos alunos e em outra a prefeitura local disponibiliza transporte público até a entrada do campus.

A gestão do Sistema de Bibliotecas (SIB) da UFRB revelou na entrevista que está em andamento a aquisição do piso tátil para o interior das bibliotecas. Com a instalação do piso tátil facilitará a biblioteca implementar a rota acessível, um recurso necessário para PDV. Na entrevista, o gestor do Núcleo de Políticas de Inclusão (NUPI) informou que o núcleo tem adquirido recursos de TA e que quase todas as bibliotecas têm scanner de voz, entretanto, destacou a falta de pessoal qualificado para atender às demandas. Dessa maneira, as bibliotecas recebem os recursos sem o devido treinamento para utilizá-los. A partir dos dados apresentados, pode-se afirmar que as bibliotecas dispõem de recursos de TA, a saber: lupa, scanner de voz, Quick Voice, mas convém ressaltar que outros disponíveis gratuitamente na internet, como os leitores de tela, poderiam ser disponibilizados.

Uma questão relativa à percepção dos bibliotecários sobre os documentos que gerenciam a biblioteca quanto à inclusão indica que estes documentos não integram a inclusão da PDV. Assim, mais de 55\% consideraram tais instrumentos insatisfatórios. A ausência de comunicação acessível provoca barreiras comunicacionais que impactam a autoestima, a autoconfiança e provocam o isolamento e a exclusão social. Nos murais, percebe-se a falta de padronização no tamanho das fontes utilizadas, há avisos em fonte ampliada e outros em tamanho pequeno. Acerca da relação dos funcionários do atendimento das bibliotecas com os estudantes com deficiência visual foi questionado como eles se sentem ao lidar com um estudante nessa condição. A maioria respondeu que se sente totalmente inseguro. A insegurança no atendimento à PDV relaciona-se diretamente com a falta de capacitação.

Acesso à literatura técnico-científica por discentes cegos da Universidade Federal do Pará (UFPA), dissertação de Pinheiro (2019), investigou os processos que envolvem o acesso à literatura técnico-científica por discentes cegos da UFPA. O estudo possibilitou que nove discentes cegos expressassem, por meio da entrevista, questões em torno de processos que envolvem o acesso à literatura técnico-científica recomendada pelos professores e necessárias para a formação acadêmica. Visualiza-se nos resultados que o formato digital é utilizado por $100 \%$ dos discentes cegos que responderam sempre utilizarem material bibliográfico neste formato, principalmente, para o acesso aos livros e artigos recomendados pelos professores. Enquanto a escrita Braille é utili- 
zada raramente por apenas dois discentes que relataram não utilizarem para o acesso de livros e artigos devido ao tempo de leitura de bibliografias em Braille, mas outras formas de documentos ou informações como, gráficos e planejamento de roteiro de aulas.

Os recursos de TA para o acesso ao material bibliográfico em formato digital mais utilizados pelos discentes cegos são o Sistema Operacional Dosvox e o leitor de tela NVDA, ambos gratuitos. Além destas duas TA, o leitor de tela JAWS é utilizado raramente por dois discentes. Ao serem investigados se utilizam serviços disponíveis pelo Espaço Braille da Biblioteca Central, sete discentes relataram que utilizam, sendo cinco sempre, o que corresponde a $55,56 \%$ dos entrevistados, e dois raramente, $22,22 \%$. Logo, aproximadamente $78 \%$ utilizam os serviços disponíveis pelo Espaço Braille.

Os serviços utilizados relatados pelos discentes são, prioritariamente, para terem acesso ao material bibliográfico em formato acessível sendo destacado por todos como: conversão de material para formato acessível, citado por todos nove discentes (100\%); pesquisa na web, citado por quatro estudantes $(44,44 \%)$; formatação de arquivos, pesquisas para buscar filmes e fotos, normalização de trabalhos acadêmicos, conversão para MP3, uso de softwares e descrição de imagens, todos citados por um discente.

Todos os discentes cegos consideram que há barreiras quanto ao acesso ao conteúdo do material bibliográfico indicado pelos professores da UFPA, sendo que as principais barreiras relatadas têm relação com a falta de acessibilidade dos materiais sendo mencionado o material em formato inacessível, citado por 66,67\%; material com imagem inacessível, citado por 33,33\%; material danificado, citado por $22,22 \%$; demora na disponibilização de material acessível, citado por 22,22\%; não recuperação da informação, citada por 11,11\%; acesso pela Coordenadoria de Acessibilidade (CoAcess) do material indicado pelo professor para posterior conversão, citado por $11,11 \%$; ausência de dados bibliográficos do livro, citado por 11,11\%; livros difíceis de digitalizar (muito antigo), citado por $11,11 \%$. Nesta passagem visualiza-se a barreira informacional que podem ser entraves e/ou obstáculos que venham a dificultar ou impossibilitar o acesso à informação.

Santos (2019), na pesquisa Inclusão digital na biblioteca universitária: desenvolvimento de competência informacional nos usuários cegos e com baixa visão do espaço acessibilidade da Biblioteca Central (BICEN), teve como objetivo geral desenvolver a competência informacional nos usuários cegos e com baixa visão, ressaltando o caráter mediador do profissional bibliotecário. Observa-se nos resultados que visto o potencial mediador de informações do Espaço Acessibilidade, entende-se que é necessário destacar a qualificação de seus servidores, pois este é um fator que contribui para a descrição da dinâmica que ali se estabelece. Novamente pode-se perceber a importância da capacitação dos funcionários das bibliotecas, seja acerca da inclusão, acessibilidade, TA, PCD dentre outros assuntos para que o atendimento, a mediação e o contado com esse público possa ser adequado, com qualidade, com respeito, empatia e equitativo se comparado ao usuário sem deficiência. Destaca-se, portanto, a relevância da acessibilidade atitudinal com a ausência de preconceitos, estigmas, estereótipos ou discriminação e a conscientização da equipe sobre a sua responsabilidade nesse contexto e da importância da convivência com a diversidade. 
Ao analisar a formação acadêmica dos servidores, pode-se inferir que apenas um servidor tem especialização na área de acessibilidade, fator que pode contribuir para sua desenvoltura funcional, visto que a sua especialização e os objetivos do Espaço Acessibilidade têm propostas afins.

As principais atividades do Espaço Acessibilidade e para que se realiza são: a) digitalização de materiais - para que materiais impressos possam ser colocados em meio digital e acessados por meio de adaptadores; b) revisão de textos em Braille avaliar a qualidade do texto adaptado; c) impressão em alto relevo - para que o indivíduo cego ou com baixa visão tenha acesso a imagens e figuras; d) gravação de voz; e) edição de textos - realizada para facilitar a leitura por meio do leitor de tela; e) disponibilização de intérprete de Libras; f) Tradução de Libras - importante para estabelecer a comunicação com pessoas surdas ou com perda auditiva; g) acompanhamento; h) treinamentos de Braille - para capacitação de colaboradores; i) transcrição de arquivos - para deixar acessível a cegos conteúdos impresso; e j) atendimento - acolhimento da PCD.

Compreende-se que os espaços acessíveis nas BU para o discente com deficiência são importantes, mas considera que um cenário mais inclusivo seria disponibilizar recursos de acessibilidade e softwares nos computadores de acesso em comum com outros usuários o que contribui para a convivência de todos, a interação, e até o conhecimento das pessoas sem deficiências de recursos informacionais e TA que existem e propiciam autonomia e independência as PCD.

Segundo os funcionários, grande parte dos serviços requeridos no Espaço Acessibilidade é fruto de necessidades pontuais dos usuários, por exemplo, a adaptação de um texto ou artigo. Ainda de acordo com os servidores, a periodicidade com que os serviços são requeridos está diretamente ligada ao ritmo adotado pelo professor em sala de aula. Diante do exposto, pode-se sugerir que a IES ao efetivar a matrícula de discentes com deficiência mantenha uma comunicação com as BU as informando que no curso que elas atendem há PCD para se prepararem, contatarem outros setores como os núcleos de inclusão para saber o que pode ser feito para o melhor atendimento a esse público, se eles já produziram materiais acessíveis que podem ser inseridos no software de gerenciamento de acervo das bibliotecas e disponibilizado aos usuários ou pedir sugestões de como ou o que a biblioteca poderia fazer para contribuir no acolhimento e percurso acadêmico desses estudantes.

O acervo do Espaço Acessibilidade é composto basicamente de materiais adaptados adquiridos por meio de doação, dentre os quais podem ser encontrados: livros, jornais, revistas e CDs com conteúdo falado. Dentre as instituições que fomentam o acervo do Espaço Acessibilidade podem ser citadas a Fundação Dorina Nowil e o Instituto Benjamin Constant. De acordo com informações do setor os livros recebidos pelo Espaço Acessibilidade passam pelo processamento técnico e etiquetagem comuns a todos os demais materiais bibliográficos da instituição. Após serem disponibilizados no acervo apenas os usuários com deficiência e com vínculo institucional podem fazer o empréstimo desse tipo de material com o prazo de empréstimo de 30 dias e sem renovação.

A comunidade atendida pelo Espaço Acessibilidade e formado por PCD auditiva (28), baixa visão (83), cegueira (10), deficiência física (169), deficiência intelectual (5), alheias ao setor (1), outras (4), surdez (19), Transtorno de déficit de atenção TDAH (2), Transtorno mental (1) Transtorno do Espectro Autista - TEA (2), visual - ou- 
tros (5) em um total de 329 PCD. Essa diversidade de pessoas atendida pelo Espaço de Acessibilidade vai ao encontro dos dados do Censo da Educação Superior, em que se vê uma multiplicidade de sujeitos informacionais em busca de formação profissional ou realização pessoal e superando as barreiras para concluírem os seus estudos. Com base nessas informações pode-se dizer que dentre esses indivíduos atendidos pelo Espaço de Acessibilidade estão os estudantes que compõem a comunidade de usuários reais e potenciais. No caso dos usuários potenciais, é importante esclarecer que não é rara a situação em que o indivíduo ingressa na universidade com a deficiência, porém sem necessidade de auxílio e que tal necessidade seja requerida no decorrer da sua vivência universitária.

O Espaço Acessibilidade possui iniciativas de inclusão digital, a saber: existem dois computadores adaptados com leitores de tela destinados aos usuários, sendo que uma dessas máquinas é equipada com uma lupa que garante o aumento da fonte do conteúdo acessado para os usuários com baixa visão e possuem equipamentos físicos e estrutura para a conexão de rede. Porém, não foram identificadas atividades que promovessem ou incentivassem o uso de tais ferramentas em prol da autonomia desses sujeitos no ciberespaço ou mesmo para conhecimento de canais de informação e, ponderando esses fatores, pode-se concluir que o Espaço Acessibilidade se encontra no primeiro estágio da inclusão digital, o acesso.

Verificou-se que dentro da biblioteca há treinamento para o público sem deficiência no qual aborda os tipos de fontes informacionais, estratégias de busca, o uso do catálogo e serviços da biblioteca. E contrariando essa perspectiva, não existem iniciativas nesse sentido para o público com deficiência. Ante ao exposto, problematizase então essa questão, qual(ais) o(s) motivo(s) para que essa prática não seja realizada também para o usuário com deficiência tendo em vista que a biblioteca tem o conhecimento desse discente na IES?

Identificou-se que dentro do Espaço Acessibilidade são realizadas ações de intermediação nas quais os funcionários se detêm, apenas, à demanda de atendimento imediata do usuário. Pontua-se a ausência do profissional bibliotecário dentro do setor. Segundo os funcionários abordados já houve a presença desse profissional no espaço e acredita-se que ele é importante. Logo, entende-se que ao considerar a natureza do trabalho que tem a informação como objeto, o bibliotecário poderia ser um agente mediador de informações para o desenvolvimento de inclusão digital no Espaço Acessibilidade. Ao que tange as necessidades de informação desses discentes pode-se concluir que elas estão atreladas às demandas das disciplinas cursadas por eles e que a busca por informações é pautada pela dinâmica delas. Os dados apontam que a procura se restringe apenas em informações didáticas relacionadas aos cursos e a falta do bibliotecário no setor pode ser um fator que agrava tal situação. Nota-se em ambas as passagens a importância da presença do bibliotecário para fazer a gestão da informação sob a perspectiva da acessibilidade, em criar produtos informacionais acessíveis e de assumir essa responsabilidade no seu fazer profissional.

Acerca das fontes de informação do espaço de acessibilidade da BICEN encontra-se: livro impresso (adaptado em áudio), fontes eletrônicas de informação, internet (fontes eletrônicas), livro impresso (uso de lupa, pois é baixa visão), livro impresso (escaneado, convertido em PDF e usado com leitor de tela), livro em PDF (online, neste caso usa apenas o leitor de tela), bases de dados eletrônicas (CAPES), livro impresso em Braille, livro impresso (PDF para leitor em NVDA). As fontes de informação mais 
utilizadas pelos usuários cegos e com baixa visão são, prioritariamente, os livros disponíveis na biblioteca, os mesmos de uso comum a todos os estudantes. O Portal de Periódicos CAPES foi uma fonte lembrada pelos usuários, um deles descreveu sua experiência: "a CAPES, mas eu nunca pesquisei sozinho não, já pedi para uma pessoa pesquisar para mim, é que a base tem muitas colunas e o Dosvox não lê a linha inteira [...]". Neste caso, o usuário tomou conhecimento da base por intermédio de um professor de metodologia que a indicou para a turma. Sinaliza-se que é evidenciada, neste ponto, a importância do mediador ou intermediador que apresente ao usuário alternativas para busca de informações.

As dificuldades no acesso à informação ocorrem em torno das limitações que os próprios adaptadores possuem, por exemplo, a impossibilidade de lidar com uma grande quantidade de material em Braille. Pois, o conteúdo que é transcrito para ele tem seu volume ampliado além da dificuldade no transporte e armazenamento desse material. Os leitores de tela não leem informações contidas em tabelas, gráficos e afins. Normalmente, os leitores leem as interfaces, livros ou textos de forma linear, quando há uma quebra dessa linearidade ou quando o texto apresenta gráficos, tabelas, imagens essas passam despercebidas pelo leitor, dificultando a compreensão do usuário em relação ao texto. A estrutura das interfaces digitais na qual a informação está disposta em colunas faz com que o leitor não leia a interface de forma linear. A não compatibilidade de plataformas como o Sistema Integrado de Gestão Acadêmica (SIGAA) com os leitores de tela que dificulta o acesso a informações referentes ao curso, à matrícula, aos serviços da universidade, à comunicação com os professores e aos materiais didáticos.

$\mathrm{Na}$ atividade de obtenção da informação os usuários do setor se utilizam do empréstimo de livros na biblioteca, da reprodução de textos requeridos em sala de aula, bem como baixam da internet os que porventura sejam de seu interesse. Acerca do uso da tecnologia todos os usuários ressaltaram limitações em relação ao seu uso conforme explicitado a seguir: Usuário 1 - Cego: tem conhecimento de informática, mas desconhecimento das bases de dados, e tem facilidade de uso do Dosvox; Usuário 2 - Baixa visão: dificuldade de usar a lupa, desconhecimento das bases de dados e do Braille e solicita treinamentos em Braille; Usuário 3 - Cego: o conteúdo das interfaces digitais, por vezes, está disposto em colunas, dessa forma, para a PCD visual há uma dificuldade de acesso por intermédio de leitores de tela e pela perda da linearidade na leitura. Usa o NVDA e ressaltou o uso dos óculos para leitura dos conteúdos, porém o valor é muito elevado $(\$ 15.000,00)$; Usuário 4 - Cego: SIGAA não acessível a PCD visual. Ele possui noções básicas com o uso do computador e domina também o uso do celular, desconhece as bases de dados; Usuário 5 - Cego: SIGAA não é acessível a PCD visual, tem facilidade com o leitor NVDA, acessa o site da CAPES para pesquisa e utiliza o NVDA; e o Usuário 6 - Baixa visão: usa o audiodescritor automático.

Verificou-se que a maioria os usuários têm acesso à internet, a computadores e sabem manusear o equipamento, porém, a forma de adaptação para o uso aparece como uma questão. Observa-se que para alguns usuários apenas os leitores são suficientes e outros demandam um pouco mais de adaptação para o uso como fica explicitado no recorte das falas dos usuários três e seis. O usuário dois aponta que é importante haver treinamentos para o uso do Braille. Ao observar as questões colocadas pelos usuários fica evidente a pluralidade que é inerente a essa comunidade. 
A dissertação de Silva (2019a), intitulada Proposta de um programa para desenvolvimento da competência em informação em bibliotecas universitárias para estudantes cegos, analisou como a competência em informação pode contribuir para o acesso e uso da informação pelos estudantes cegos nas BU de Santa Catarina. A análise e discussão dos resultados é composta por nove categorias das quais apresentam-se alguns aspectos. Na categoria Frequência à biblioteca universitária - dos três estudantes que afirmam frequentar a BU a relacionam apenas como ambiente para estudo. Isso evidencia que possa haver alguma falta de conhecimento de outras possibilidades para uso delas. Pelo fato de grande parte dos estudantes não usarem a biblioteca um dos motivos pode ser o desconhecimento dos recursos de informação disponíveis nos ambientes (virtual e físico). Observa-se a necessidade de a biblioteca/ criar ações no quesito da acessibilidade comunicacional e atitudinal sobre a divulgação dos serviços e atividades oferecidas assim como planejar ações que despertem a vontade desses estudantes em usarem a biblioteca. É preciso que as bibliotecas estejam preparadas tanto na infraestrutura quanto na formação das pessoas que prestam serviços para que elas ofereçam possibilidades de acesso e uso da informação para diferentes grupos com diferentes necessidades informacionais que podem ser na forma física, presencialmente, ou digital por acesso remoto.

Acerca da Acessibilidade física na biblioteca a maioria dos estudantes cegos afirmam que estiveram poucas vezes nesse ambiente e que conheceram todos os setores dela em um único momento quando a universidade fez a visita guiada nos setores. Nesta dimensão da acessibilidade os estudantes relataram que as dificuldades são:

[...] não tem identificação nenhuma em Braille nem aplicativo que possa estar falando quais os livros que estão nas prateleiras de que tipo que estão, a localização deles, o espaço é muito estreito, muito ruim para a gente se locomover lá dentro da biblioteca. Ninguém me deu aulas de orientações. [E3] Não acho acessivel e não vou te dizer que dominei o caminho para chegar até lá, achei um pouquinho confuso. Não andei muito e fui com uma pessoa que me acompanhou. O elevador daqui é minimamente acessivel, só tem o Braille e precisa de uma identificação sonora, senão quando a gente chega no andar a gente não sabe onde está. Só sabemos quando descemos e passamos a mão na parede para ver o número que está ali, caso contrário não tem nenhum som que direciona. [E4]

Para mim só tem plaquinha de acessibilidade porque os locais que é para ser acessivel não é. Conversando com as meninas do Programa de Promoção a Acessibilidade (PPA) acabei não ficando na biblioteca. [E5]

Eu uso só os espaços das salas, então não sei como são os outros lados da biblioteca. A moça da biblioteca sempre me traz até as salas porque dentro da biblioteca não temos o piso guia. Não tem identificação nem em Braille nem nada. [E6]

O acesso físico para entrar e sair aparentemente não tem problema. Eu não sei como estão dispostos os livros, se mapa tátil, se tem Braille se não tem por que não tenho interesse [...] porque se eu entrar em uma biblioteca eu vou ter problemas e aí vou me estressar, então deixa me estressar na biblioteca virtual. [E7]

Eu acho que tem muita coisa no meio, muitas mesas e muito maldispostas. Uma vez tinha plantas eu não sei se tem ainda. [E9]

Só tem piso tátil aqui embaixo no térreo, lá em cima não. Quando preciso ir lá alguém tem que me dizer onde é eu tenho que memorizar e depois com uso da bengala eu me oriento. [E10] 
É difícil porque tem esse piso guia que só vem até o Ambiente de Acessibilidade Informacional (AAl) e banheiro e não vai para o resto da biblioteca e, às vezes, é um espaço muito aberto. É ruim por isso não venho muito porque não é um ambiente que eu me sinta confortável para vir sozinha. Não me sinto totalmente tranquila para usar a biblioteca de boa e ficar procurando alguém para me ajudar. [E12]

Falta melhorar um pouco o espaço físico com relação a acessibilidade arquitetônica, lá em cima não tem nada. Tem piso guia só da catraca para cá. Na entrada da biblioteca não tem. O piso guia vai para o banheiro ou para o $A A l$, ou seja, a gente também tem que ir lá em cima, também tem que frequentar. [E13] (SILVA, 2019a, p. 127).

Quanto ao Acervo e recursos de informação da BU observou-se nos relatos que todos os estudantes desconhecem os recursos de informação oferecidos pelas bibliotecas. Percebe-se também que quando os estudantes cegos necessitam de recursos informacionais acessíveis ou de acesso à informação para sua demanda acadêmica esse acesso não ocorre via bibliotecário, mas sim pelas pessoas que atuam nos setores de acessibilidade das universidades como mencionado em dois depoimentos. Infere-se que esse cenário pode dificultar para que o bibliotecário conheça as reais necessidades do público cego e dos recursos que utilizam como também o desconhecimento quanto às possibilidades que a BU oferece para auxílio no aprendizado além daquelas oferecidas pelos setores de acessibilidade. Pelas barreiras e dificuldades encontradas pelos usuários cegos eles usaram poucos recursos de informação da BU. A falta de uso de padrões de acessibilidade nos sites das bibliotecas prejudica o desempenho dos estudantes para acessar e usar a informação, bem como os afasta da biblioteca. É preciso compreender que a acessibilidade, tanto no espaço físico quando no virtual, precisam caminhar juntas. Tem-se o entendimento de que a acessibilidade deveria ser naturalizada em todos os processos das bibliotecas. Em que quando fosse criar, disponibilizar, treinar, organizar dentre outras atividades que envolvem a informação e/ou contato com o usuário esse aspecto estivesse presente.

Em geral, os relatos evidenciam a necessidade de ações para diminuir barreiras atitudinais e de comunicação, pois, dos 13 estudantes cegos entrevistados 11 deles afirmam serem necessárias algumas melhorias na divulgação dos serviços de informação oferecidos pelas BU e a necessidade de bibliografias da área do seu curso em formatos acessíveis.

Na categoria Atendimento prestado aos usuários na biblioteca dos 13 estudantes entrevistados, 11 estudantes afirmam que o atendimento foi bom, excelente, normal, geralmente bom, ótimo e legal. Dois estudantes relataram não terem sido bem atendidos quando estiveram na biblioteca acompanhados por outros estudantes videntes e que o atendente direcionava a comunicação aos amigos e não diretamente a eles. Observa-se nos relatos que as melhorias sugeridas pelos estudantes cegos quanto ao atendimento prestado pelas BU estão relacionadas às necessidades do conhecimento das bases de dados; capacitação das pessoas para atender o público dos estudantes cegos; materiais bibliográficos adaptados; acessibilidade digital; dificuldade dos atendentes em relação à compreensão da necessidade informacional do estudante cego; pouco tempo de uso da biblioteca; melhorias no tratamento pessoal, orientação e divulgação dos recursos informacionais e necessidade de serem incluídos nos demais espaços da biblioteca. De acordo com os relatos apresentados é possível observar a importância de ter um programa de competência em informação nas bibliotecas pes- 
quisadas. Esse programa deve contemplar tanto a capacitação da equipe da biblioteca para o atendimento desse público específico quanto para atendimento das necessidades informacionais dos estudantes cegos que têm perfil e necessidades diferenciadas dos demais estudantes. Nas sugestões dadas pelos discentes com deficiência nota-se que são aspectos relacionados a acessibilidade nas dimensões informacional, atitudinal e comunicacional.

Diante do contexto apresentado, verifica-se que, para melhorar o acesso à informação e recursos disponíveis nos ambientes físico e virtual das BU pelos estudantes cegos e ampliar o atendimento dos diversos públicos, é prioritário melhorar o atendimento prestado por estas UI. Para isso, os bibliotecários precisam interagir com os estudantes cegos para compreender suas necessidades, para melhorar sua comunicação e tratamento pessoal.

Quanto aos Serviços e produtos de informação, os estudantes citaram o uso dos seguintes serviços informacionais: livros acessíveis didáticos e complementares, empréstimo domiciliar, computadores com leitores de tela, manual digital com orientações para trabalhos acadêmicos, base de dados (Scielo e Lilacs), site da universidade, site da biblioteca (catálogo de livros) e buscador Google. A maioria dos estudantes cita o livro como principal serviço e produto de informação oferecido pelas bibliotecas considerando o ambiente virtual da biblioteca e da universidade para acesso aos mesmos. No entanto, os estudantes cegos sentem dificuldades devido à falta de acessibilidade digital e física, como também ausência de bibliografias complementares adaptadas. Um estudante menciona que ele tem a necessidade de pessoas capacitadas em TA para a oferta de serviços e produtos de informação acessíveis. Verifica-se, também, a necessidade de as bibliotecas oferecerem programas para a inclusão digital conforme o relato de um estudante. Desenvolver a competência em informação dos estudantes cegos para o uso eficiente da informação é, também, facilitar o acesso aos recursos e serviços de informação presencial e virtual disponibilizados pelas bibliotecas para o exercício da sua cidadania e dos direitos constitucionais comuns às demais pessoas.

$\mathrm{Na}$ categoria Formato de leitura todos os estudantes cegos relataram usar o formato digital como acessível nas extensões do Word e PDF para leitura e acesso à informação disponível pelas bibliotecas nos ambientes físico e virtual. Dois estudantes relataram usar o formato áudio para leitura por não conhecerem o Braille e por gostarem de recursos digitais. Os demais não o usam por ter configuração própria, não ter o hábito, tem preferência por ler e não ouvir, muito lento, velocidade de leitura inferior, não se adaptar, a leitura não é no ritmo ideal, não ter paciência e ocupa muito espaço.

Quanto ao formato digital todos os estudantes cegos relatam usar devido ser mais fácil de manipular ou mexer, gravam vários documentos em um pen drive com leitor de telas apropriado, conseguem converter arquivos em áudio, são mais fáceis e mais rápidos, não gostam ou não se adaptam com outros formatos, propicia maior independência na navegabilidade do conteúdo, traz agilidade, deixa um pouco mais igual, mais fácil de encontrar conteúdos acessíveis, possibilidade para ler em velocidade que deseja, escolha de vozes sintetizadores, permite maior manipulação quanto ao aumento de fonte ou alterações sem perder fórmulas ou dados, é o que está mais acessível, tem facilidade para transportar, é mais fácil para navegar e tem a facilidade de uso em diferentes equipamentos (celulares, computadores, Ipad e outros).

Infere-se que as bibliotecas ao produzirem e disseminarem algum documento nas extensões Word e PDF que verifiquem a acessibilidade do material elaborado. Um 
exemplo é no próprio Word, no menu Revisão - Verificar Acessibilidade ao selecionar esta opção ela apresentará os resultados da inspeção para que se possa fazer as alterações. Compreende-se que são ações simples, mas que auxilia no acesso à informação para a PDV.

Na categoria TA foi possível identificar quais tecnologias e softwares para auxílio na leitura são mais utilizadas pelos estudantes cegos para terem acesso às informações e conteúdos literários. De acordo com os relatos dos foram identificados softwares, aplicativos, equipamentos ou outro recurso, sendo eles: Non Visual Desktop Access (NVDA), Job Access With Speech (JAWS), Linha Braille ou display Braille, Lupa digital, Adobe Acrobat e Adobe Reader, Microsoft Word, Bloco de notas, Celular, computador, tablet, Tap TapSee, Seeing Al, Câmara tradutora do Google tradutor, Talkback para celulares (androide), Reglete para assinaturas, Voice Over para celulares Iphone, Prisma do Google, WhatsApp, Facebook, Google play livros, Electronic Publication - Epub (formato de arquivo padrão para e-books), Balabolka (leitor), Ampliadores de tela do computador, Braille (uso em mapas geográficos), Gravador, Teclado bluetooth, Sintetizadores de vozes: Raquel e Luciana, Impressora Braille. Pondera-se que dos recursos tecnológicos informados pelos estudantes com deficiência visual alguns deles podem ser desconhecidos pelos funcionários das bibliotecas. E que esse desconhecimento pode implicar para a inacessibilidade das BU.

De acordo com os relatos acerca da categoria Dificuldades para acessar informações, as principais dificuldades encontradas pelos estudantes cegos para acesso à informação nos ambientes das bibliotecas são: materiais com imagens, gráficos e figuras as quais os leitores não leem; pessoas não qualificadas para fazer a transcrição ou adaptação de materiais bibliográficos de acordo com cada área do conhecimento; não conseguir acessar nada devido à falta de acessibilidade, conhecimento e não ter pessoas para auxiliar; nunca ter usado o formato impresso; não saber o que tem de formato impresso na biblioteca para cegos; não ter acessibilidade nos ambientes virtuais e nos documentos no formato digital; não ter materiais acessíveis nos formatos impresso ou adaptado nas BU; demora na conversão de materiais bibliográficos para formato acessível; poucas pessoas para fazer a conversão para materiais acessíveis; arquivos PDF em formato de imagens; uso do Captcha (recurso de segurança) não permite fazer login e acessar conteúdo na internet; design não amigável e falta de preocupação ergonômica no ambiente virtual; leitura em Braille não fluente; estrutura dos sites complexos e os leitores não funcionam; falta de acessibilidade sonora nos elevadores, sites ou sistemas digitais; não saber usar scanner. Diante do exposto, pode identificar algumas barreiras como a informacional, a comunicacional e a inacessibilidade na web.

Na categoria Percepções dos estudantes cegos sobre a BU foi solicitado aos estudantes cegos para deixarem comentários gerais sobre suas percepções quanto a ela. Identificou-se nos relatos dos estudantes que há a necessidade de mais conteúdos bibliográficos acessíveis não somente das bibliografias básicas, mas também das complementares, identificação nos espaços físicos com pisos táteis, identificação sonora inclusive nos sistemas de gestão dos recursos informacionais das bibliotecas, identificação em Braille nos ambientes físicos a exemplo das prateleiras e demais equipamentos, criar espaços físicos para estudantes cegos dentro dos espaços das BU e não somente aqueles dos setores de acessibilidade das universidades. 
A análise das sugestões apresentadas também evidencia melhorias e necessidades para saber onde encontrar os recursos informacionais; divulgar mais o que a BU oferece; oferecer capacitação inclusive para os funcionários conseguirem atender meIhor a diversidade de PCD; melhorar a comunicação para o estudante cego ficar ciente do que tem e não tem nos ambientes virtual e físico da BU; necessidade e vontade para explorar mais os ambientes da BU e poder participar com sugestões para melhorias na acessibilidade dos serviços informacionais e ambientes; informar mais aos estudantes cegos sobre os acervos da BU; oferecer aulas sobre o uso da biblioteca para ensinar a usar os recursos de informação; saber fazer uso ao menos daquilo que está disponível e acessível; indicação de fontes de informação; mais inclusão nos outros espaços não somente no setor de acessibilidade; melhorar o contato como o estudante cego; as informações não estão disponíveis de um jeito fácil; as informações não ficam centralizadas; conseguir acessar os materiais bibliográficos com mais facilidade; facilitar o acesso aos materiais bibliográficos; incluir mais os estudantes cegos para que consigam ter as mesmas condições dos demais estudantes com visão. Ante o exposto pode-se perceber que as sugestões estão associadas as barreiras informacionais, de comunicação, atitudinal, na web, da necessidade de uma postura proativa da equipe da biblioteca, do marketing da BU para disseminar os seus serviços dando maior visibilidade ao que ela tem e realiza.

Observa-se que, coincidentemente, todas as investigações apresentadas tiveram como objeto de estudo a deficiência visual, as pessoas cegas ou com baixa visão. Visualiza-se que mesmo com o interesse no usuário com deficiência visual como objeto de estudo as BU, ainda, apresentam barreiras a esse público conforme se pode observar nos resultados e nas falas dos interlocutores em investigações recentes.

Diante desse cenário infere-se que, talvez, falte conhecimento da legislação brasileira, da literatura nacional e internacional sobre a temática, de normas técnicas, do contexto da PCD, das TA etc. por parte de alguns gestores, bibliotecários e membros da equipe que impedem uma avaliação e reflexão acerca dessa questão nas BU brasileiras. Bem como da falta de compreensão sobre o papel que as BU têm nesse contexto com o compromisso de dar o acesso e disseminar informações para uma diversidade de usuários.

Diante dos relatos apresentados pondera-se que esse cenário nas bibliotecas ainda persista devido a algumas razões como o desinteresse pessoal para essa questão, a falta de recursos financeiros e que o recurso que as BU recebem pode não ser destinado para ações inclusivas, a falta de uma cultura inclusiva e política institucional e do entendimento de que contemplar a acessibilidade e a inclusão na gestão das BU e na prática profissional é uma responsabilidade social dos bibliotecários.

Sabe-se que a presença desses cidadãos no ensino superior já é um fato, mas ações que caminhem na direção da inclusão e acessibilidade para diminuírem a inacessibilidade nas UI parecem não acompanhar essa realidade. De acordo com Silva (2019a, p. 162), “o processo de acessibilidade e a inclusão social são asseguradas por uma ampla legislação nacional e internacional". E que a falta de acesso à informação conforme relatado por estudantes cegos no universo das BU está relacionada com as barreiras de acessibilidade arquitetônica, comunicacional, metodológica, instrumental, programática e atitudinal definidas por Sassaki (2006).

Cabe destacar que o propósito fundamental da BU "é proporcionar acesso ao conhecimento. Esse acesso ao conhecimento é que irá permitir que o estudante, o professor e o pesquisador possam realizar suas aprendizagens ao longo da vida" (CUNHA, 2010, p. 7). E a 
preocupação quanto ao acesso à informação pode ser destacada no atual cenário da pandemia do novo Coronavírus ${ }^{4}$ com o fechamento de bibliotecas.

Bibliotecas de todo o mundo "estão enfrentando escolhas difíceis acerca de quais serviços oferecer e de que forma, variando de restrições mínimas até o fechamento total" (International Federation of Library Associations and Institutions, 2020, online). O que preocupa, pois, as bibliotecas podem ser o único espaço para o acesso à informação, o estudo, lazer e espaço de interação para alguns cidadãos, incluindo aqueles que podem ter algum tipo de deficiência. Com o fechamento total ou parcial das bibliotecas elas estão se reorganizando para a prestação de serviços remotamente, realizando a comunicação constante com os usuários sobre o uso de recursos digitais e serviços online, incentivando o uso de bibliotecas digitais e outras ferramentas, organizando contação de histórias digitais, realizando atendimentos com hora marcada, lives e webinário dentre outras ações.

Ainda, acerca do contexto da pandemia, preocupações surgem com a falta de recursos de acessibilidade ou conhecimento para a realização de palestras ou treinamentos online, para que discentes com deficiência possam acessar e acompanhar os conteúdos das aulas remotas via plataformas adotadas pelas IES, o que neste segundo caso pode causar evasão, trancamento de disciplinas, ocasionando, assim, prejuízos para essas pessoas. Portanto, esse cenário aflora para se repensar e discutir o trabalho do bibliotecário e o papel das BU para a questão da diversidade e da inclusão para a redução das desigualdades.

Em face disso, infere-se que seja necessário repensar acerca dos serviços e produtos disponibilizados pelas UI, pois, sendo muitos deles exclusivamente presenciais, podem não levar informações aos seus usuários e ampliar, assim, a exclusão nesse espaço social. E, mais especificamente, para aqueles que têm deficiência e que diante de especificidades para o acesso à informação exigir-se-á das BU mudanças para disseminação e compartilhamento de informações. Ressalta-se que, como dispõe a Lei Brasileira da Inclusão, Art. 84, "a pessoa com deficiência tem assegurado o direito ao exercício de sua capacidade legal em igualdade de condições com as demais pessoas" (BRASIL, 2015, on-line). Sendo assim, a discussão realizada ampara-se, sobretudo, sobre o direito das PCD ao acesso à informação e, consequentemente, no papel das UI em garantir ou se esforçar para realizar a inclusão e a acessibilidade em seus espaços físico e virtual (sites, redes sociais).

Apreende-se que, com a literatura acerca dessa temática juntamente com os resultados apresentados em diversas pesquisas na $\mathrm{Cl}$, os gestores e bibliotecários têm à sua disposição embasamentos para realizarem, na prática, a inclusão e a acessibilidade nas BU.

\section{CONSIDERAÇÕES FINAIS}

Com o desenvolvimento desta pesquisa verificou-se o grande interesse pela deficiência visual como objeto de estudo. Constata-se, assim, que muitas tipologias de deficiência não são contempladas. Dessa forma, depreende-se que ainda há muito o que conhecer desses usuários da informação e, por conseguinte, ações a serem realizadas nas BU. Principalmente com usuários com deficiências não aparentes em que no primeiro contato com o bibliotecário ou o colaborador da biblioteca não consegue identificar.

Observou-se que a maioria dos PSI ofertados para os usuários com essa tipologia de deficiência foram criados nos últimos 30 anos, o que permite inferir que muitos dos serviços disponibilizados atualmente podem não atender mais as demandas desse público como an-

\footnotetext{
${ }^{4}$ A covid-19 é uma doença causada pelo coronavírus, denominado SARS-CoV-2, que apresenta um espectro clínico, variando de infecções assintomáticas a quadros graves (BRASIL, 2020, online).
} 
tes. Portanto, a barreira informacional está presente o que prejudica, por exemplo, aos cegos acessarem o conteúdo do material bibliográfico indicado por seus professores.

Destaca-se a presença da barreira arquitetônica nos espaços internos e no entorno da biblioteca o que dificulta ou até impossibilita o usuário com deficiência física e/ou cego de frequentar a BU. Verifica-se a ausência do piso tátil que facilita a locomoção e é um recurso necessário para PDV.

Em algumas bibliotecas e/ou espaços de acessibilidade há recursos de TA, entretanto, identifica-se a falta de pessoal qualificado para atender às demandas dos usuários. Destacase, portanto, a necessidade de capacitar a equipe sempre que novos recursos tecnológicos são disponibilizados na biblioteca. Bem como observa-se a ausência do bibliotecário na equipe dos espaços de acessibilidade.

Acerca dos documentos que gerenciam a inclusão nas bibliotecas verifica-se que eles não integram a inclusão da PDV. Assim, muitos interlocutores das pesquisas consideram tais instrumentos insatisfatórios. Pondera-se que ter nos documentos normativos como o regimento, regulamento, guia de usuário, política de desenvolvimento de acervo, plano de contingência dentre outros os aspectos da acessibilidade, inclusão e usuários com deficiência contribui altamente para uma cultura e práticas inclusivas. Por conseguinte, na redução das desigualdades.

A ausência de comunicação acessível acarreta barreiras comunicacionais que podem impactar negativamente na autoestima, na autoconfiança dos usuários e, consequentemente, provocam o seu distanciamento da BU e a exclusão social.

Nota-se a insegurança de funcionários do atendimento das bibliotecas com os estudantes com deficiência visual. E essa insegurança está diretamente relacionada com a falta de capacitação. $O$ que pode ocorrer no atendimento de usuários com outras tipologias de deficiência como as mencionadas no Censo da Educação Superior.

Pondera-se que diante da multiplicidade de PCD presentes no ensino superior, as dificuldades relatadas pelas PDV e suas sugestões podem ser consideradas indicadores para tomada de decisão no contexto da inclusão nas BU. Como também a prática dos estudos de usuários nas bibliotecas possibilita aproximar desse público e conhecer suas demandas e recursos para uso das bibliotecas e o acesso à informação.

Tem-se a compreensão de que, em um primeiro momento, tornar as BU acessíveis a essa diversidade de pessoas pode ser um trabalho difícil e desafiador, mas, mesmo com obstáculos esforços precisariam ser realizados para a construção de bibliotecas acessíveis. Alerta-se da importância de conhecer os subsídios legais, marcos históricos, literatura científica, documentos nacionais e internacionais que discorrem sobre o direito dessas pessoas, que orientam em como implementar ações, que compartilham relatos dos usuários e práticas que podem contribuir para o início das mudanças nas UI. Neste ponto ressalta-se a barreira atitudinal que em alguns casos pode ser este o motivo de ainda nos depararmos com bibliotecas inacessíveis. Cabe ressaltar que quando se fala em acessibilidade ela não se restringe ou se limita ao cotidiano das PCD, mas ela beneficia as pessoas idosas, obesas, mulheres grávidas e demais cidadãos com alguma limitação momentânea, sendo esses apenas alguns exemplos.

Para o atendimento às demandas das PCD nas BU e a prática da acessibilidade informacional, comunicacional, pragmática, entre outras, os serviços e produtos da BU poderiam ser adaptados e desenvolvidos para atender às necessidades específicas do indivíduo. Tornase necessário identificar as demandas de capacitação da equipe para o atendimento a esse público. Ou seja, o usuário com deficiência precisaria se tornar o foco desse processo obser- 
vando-se as especificidades das tipologias de deficiência. Dessa forma, o atendimento tornase único, individualizado, não somente porque essa pessoa tem uma deficiência, mas porque qualquer usuário de biblioteca é único em seu comportamento informacional.

Enfim, diante da literatura apresentada visualiza-se que muitas ações ainda podem e precisam ser realizadas nas BU no contexto da acessibilidade e a inclusão da PCD não se limitando à deficiência visual, de como é importante o trabalho do bibliotecário na gestão da biblioteca na perspectiva da diversidade, da pertinência dessa discussão para a eliminação de barreiras que ainda se fazem presentes nas UI e da necessidade de conscientização do papel dos profissionais que atuam diretamente em espaços que possuem e atendem às PCD.

\section{REFERÊNCIAS}

BOLT, N.; WYBER, S. Library service to people with disabilities. 2017. Disponível em: https://www.ifla.org/ES/publications/node/47193?og=7409. Acesso em: 28 abr. 2021.

BOOLT, T.; AINSCOW, M. Index para a inclusão: desenvolvendo a aprendizagem e a participação nas escolas. Tradução: Mônica Pereira dos Santos, João Batista Esteves. Bristol: CSIE, 2012. Título original: Index for Inclusion: developing learning and participation in schools. ISBN 978-1-872001-68-5.

BRASIL. Lei no 8.213, de 24 de julho de 1991. Dispõe sobre os Planos de Benefícios da Previdência Social e dá outras providências. Disponível em:

http://www.planalto.gov.br/ccivil_03/LEIS/L8213cons.htm. Acesso em: 28 abr. 2021.

BRASIL. Lei no 13.146, de 06 de julho de 2015. Institui a Lei Brasileira de Inclusão da Pessoa com Deficiência (Estatuto da Pessoa com Deficiência). Disponível em:

http://www.planalto.gov.br/ccivil_03/_ato2015-2018/2015/lei/l13146.htm. Acesso em: 28 abr. 2021.

BRASIL. Lei no 13.409, de 28 de dezembro de 2016. Altera a Lei $n^{\circ} 12.711$, de 29 de agosto de 2012, para dispor sobre a reserva de vagas para pessoas com deficiência nos cursos técnico de nível médio e superior das instituições federais de ensino. Disponível em:

http://www.planalto.gov.br/ccivil_03/_ato2015-2018/2016/Lei/L13409.htm. Acesso em: 28 abr. 2021.

BRASIL. Decreto no 9.508, de 24 de setembro de 2018. Reserva às pessoas com deficiência percentual de cargos e de empregos públicos ofertados em concursos públicos e em processos seletivos no âmbito da administração pública federal direta e indireta. Disponível em: http://www.planalto.gov.br/ccivil_03/_ato2015-2018/2018/decreto/d9508.htm. Acesso em: 28 abr. 2021.

BRASIL. Ministério da Saúde. O que é COVID-19? [2020]. Disponível em: https://coronavirus.saude.gov.br/sobre-a-doenca. Acesso em: 28 abr. 2021.

CAMPOS, V. B. Os desafios do acesso e da permanência de pessoas com deficiência na educação superior. In: SEMINÁRIO NACIONAL DE EDUCAÇÃO SUPERIOR, 6.; ENCONTRO DE PESQUISADORES EM EDUCAÇÃO ESPECIAL E INCLUSÃO ESCOLAR, 5., 2014, Uberlândia. Disponí- 
vel em: http://docplayer.com.br/16242107-Os-desafios-do-acesso-e-da-permanencia-depessoas-com-deficiencia-na-educacao-superior.html. Acesso em: 28 abr. 2021.

CERQUEIRA, F. de J. A inclusão da pessoa com deficiência visual sob a perspectiva da Ciência da Informação: um estudo nas bibliotecas da UFRB. 2019 Dissertação (Mestrado em Ciência da Informação) - Pós-Graduação em Ciência da Informação, Universidade Federal da Bahia, 2019.

CORDEIRO, A. M.; OLIVEIRA, G. M. de; RENTERÍA, J. M.; GUIMARÃES, C. A. Revisão sistemática: uma revisão narrativa. Revista do Colégio Brasileiro de Cirurgiões, Rio de Janeiro, v. 34, n. 6, p. 428-431, 2007.

CUNHA, M. B da. A biblioteca universitária na encruzilhada. DataGramaZero: Revista de Ciência da Informação, Rio de Janeiro, v. 11, n.6, dez. 2010. Disponível em: http://repositorio.unb.br/handle/10482/14869. Acesso em: 28 abr. 2021.

CUNHA, M. B. da; CAVALCANTI, C. R. de O. Dicionário de biblioteconomia e arquivologia. Brasília: Briquet de Lemos, 2008.

CUNHA, M. B. da; AMARAL, S.A. do; DANTAS, E. B. Manual de estudos de usuários da informação. São Paulo: Atlas, 2015.

FERNANDES, J. D. P. B. Diagnóstico da acessibilidade informacional na biblioteconomia brasileira. 2018. Dissertação (Mestrado em Ciência da Informação) - Universidade Federal do Ceará, Fortaleza, 2018.

INTERNATIONAL FEDERATION OF LIBRARY ASSOCIATIONS AND INSTITUTIONS (IFLA). A COVID-19 e o Setor de Bibliotecas em Termos Mundiais. Tradução: Lívia Aguiar Salomão. Revisão: Miguel Araujo de Matos. Brasília: Setrin/SGIDOC, 2020. Disponível em: https://www.ifla.org/files/assets/hq/topics/libraries-development/documents/covid19_and_the_global_library_field-pt.pdf. Acesso em: 28 abr. 2021. Título original: COVID-19 and the Global Library Field.

INSTITUTO NACIONAL DE ESTUDOS E PESQUISAS EDUCACIONAIS ANÍSIO TEIXEIRA (INEP). Resumo técnico do Censo da Educação Superior 2017. 2019. Disponível em: http://portal.inep.gov.br/informacao-da-publicacao//asset_publisher/6JYIsGMAMkW1/document/id/6725796. Acesso em: 28 abr. 2021.

LANNA Júnior, M. C. M. (Comp.). História do Movimento Político das Pessoas com Deficiência no Brasil. - Brasília: Secretaria de Direitos Humanos. Secretaria Nacional de Promoção dos Direitos da Pessoa com Deficiência, 2010.

LEMOS, J. C.; CHAHINI, T. H. C. Tecnologias assistivas nas bibliotecas universitárias. Brazilian Journal of Development, Curitiba, v. 5, n. 12, p.32517-32531 dec. 2019 Disponível em: https://www.brazilianjournals.com/index.php/BRJD/article/view/5675/5122. Acesso em: 28 abr. 2021. 
MALHEIROS, T. M. de C. Produtos e serviços de informação para pessoas com deficiência visual. 2019. Tese (Doutorado em Ciência da Informação) - Programa de Pós-Graduação em Ciência da Informação, Universidade de Brasília, Brasília, 2019.

MAIOR, I. M. M. de L. Movimento político das pessoas com deficiência: reflexões sobre a conquista de direitos. 2017. Inc.Soc., Brasília, DF, v.10 n.2, p.28-36, jan./jun. 2017. Disponível em: http://revista.ibict.br/inclusao/article/view/4029. Acesso em: 28 abr. 2021.

MEDEIROS, F. G. G.; PRESSER, N. H. Informação e inclusão social: perspectivas possíveis. Ci. Inf. Rev., Maceió, v. 7, n. 1, p. 19-33, jan./ abr. 2020. Disponível em:

https://www.seer.ufal.br/index.php/cir/article/view/9282/7404. Acesso em: 28 abr. 2021.

NICOLETTI, T. F. Checklist para bibliotecas: um instrumento de acessibilidade. 2010. TrabaIho de Conclusão de Curso (Bacharelado em Biblioteconomia) - Universidade Federal do Rio Grande do Sul, Porto Alegre, RS, 2010.

ORGANIZAÇÃO DAS NAÇÕES UNIDAS (ONU). Transformando nosso mundo: a Agenda 2030 para o desenvolvimento sustentável. Rio de Janeiro: UNIC Rio, 2016. Disponível em: https://brasil.un.org/sites/default/files/2020-09/agenda2030-pt-br.pdf. Acesso em: 28 abr. 2021.

PINHEIRO, A. L. Acesso à literatura técnico-científica por discentes cegos da universidade federal do Pará. 2019. Dissertação (Mestrado em Ciência da Informação) - Programa de Pós-graduação em Ciência da Informação, Universidade Federal do Pará, 2019.

RENDÓN-ROJAS, M. A.; GARCÍA-CERVANTES, A. El sujeito informacional em el contexto contemporâneo: um análisis desde la epistemologia de la identidade comunitária-informacional. Encontros Bibli: revista eletrônica de biblioteconomia e ciência da informação, Florianópolis, v. 17, n. 33, p. 30-45, jan./abr., 2012. Disponível em:

https://periodicos.ufsc.br/index.php/eb/article/view/1518-2924.2012v17n33p30/21709. Acesso em: 28 abr. 2021.

SANTOS, Anaise de Santana. Inclusão digital na biblioteca universitária: desenvolvimento de competência informacional nos usuários cegos e com baixa visão do espaço acessibilidade da BICEN. 2019. Dissertação (Mestrado em Ciência da Informação) - Programa de PósGraduação em Ciência da Informação, Universidade Federal de Sergipe, São Cristóvão, 2019.

SANTOS, C. G. dos; ARAÚJO, W. J. de. Acessibilidade Informacional: um estudo sobre configurações de segurança em objetos digitais acessíveis segundo análise de aceitação por pessoas com deficiência visual. Pesq. Bras. em Ci. da Inf. e Bib., João Pessoa, v. 10, n. 2, p. 209222, 2015. Disponível em: . Acesso em: 14 abr. 2018.

SASSAKI, R. K. Construindo uma sociedade para todos. Rio de Janeiro: WVA, 2006.

SILVA, A. F. da. Proposta de um programa para desenvolvimento da competência em informação em bibliotecas universitárias para estudantes cegos. 2019. Dissertação (Mestra- 
do) - Universidade do Estado de Santa Catarina, Centro de Ciências Humanas e da Educação, Programa de Pós-Graduação em Gestão de Unidades de Informação, Florianópolis, 2019.

YOSHIDA, M. A. G. B. Pessoas com deficiência: legislação, acessibilidade e trabalho. BEPA Boletim Epidemiológico Paulista, v. 5, n. 57, São Paulo, set. 2008. Disponível em: http://periodicos.ses.sp.bvs.br/pdf/bepa/v5n57/v5n57a02.pdf. Acesso: 28 abr. 2021. 